\title{
Modelagem em Vídeo para o Ensino de Habilidades de Comunicaçấo a Indivíduos COM AutisMo: ReVISÃo de EsTudos ${ }^{1}$ VIDEO Modeling FOR TEACHING COMMUNICATION SKILLS TO INDIVIDUALS WITH AUTISM: STUDY REVIEW
}

\author{
Viviane RODRIGUES ${ }^{2}$ \\ Maria Amélia ALMEIDA ${ }^{3}$
}

\begin{abstract}
RESUMO: as pessoas com transtorno do espectro autista (TEA) apresentam limitaçôes específicas nas habilidades de comunicação. A modelagem em vídeo (MV) é considerada uma prática baseada em evidências para indivíduos com TEA pelo fato desta população preferir e responder melhor às estratégias de ensino por meio de pistas visuais. Neste sentido, o objetivo desta revisão foi discutir os resultados das intervençôes que implementaram a MV para ensinar habilidades de comunicação para indivíduos com TEA. Para tanto, três critérios de inclusão foram estabelecidos, sendo eles: a) os estudos deveriam utilizar como variável independente a modelagem em vídeo isoladamente, associada a outra intervenção ou como parte de um pacote de tratamentos; b) as habilidades de comunicação deveriam fazer parte da variável dependente, mesmo que estivessem presentes outras habilidades; c) todos os estudos deveriam ter participantes com Transtorno do Espectro Autista. Foi utilizado como banco de dados o Portal de Periódico da CAPES, com descritores específicos. O período determinado neste estudo foi de 2010 a 2016. Somente 11 artigos apresentaram os critérios de inclusão determinados neste estudo. Estes estudos enfatizaram os ganhos da pessoa com TEA em suas habilidades de comunicação por meio da MV. Dados os resultados positivos relatados nestes 11 estudos, há evidências suficientes para concluir que a MV é um procedimento indicado para ensinar uma variedade de habilidades comunicativas para crianças com TEA. Conclui-se que este estudo sumarizou intervenções que empregaram a MV para o ensino de habilidades de comunicação, proporcionando direçóes para pesquisas futuras.
\end{abstract}

PALAVRAS-CHAVE: Educação Especial. Transtorno do Espectro Autista. Modelagem em Vídeo. Habilidades de Comunicação.

\begin{abstract}
People with autism spectrum disorder (ASD) have specific limitations on communication skills in both receptive and expressive language. Video modeling (VM) is considered an evidence-based practice for individuals with ASD since this population prefers and responds better to teaching strategies through visual cues. In this sense, the objective of this review was to discuss the outcomes of interventions that implemented MV to teach communication skills to individuals with ASD. Thus, three inclusion criteria were established: a) the studies should use the video modeling alone as independent variable, associated with another intervention or as part of a package of treatments; b) communication skills should be part of the dependent variable, even if other skills were present; c) All studies should have participants with Autism Spectrum Disorder. The CAPES Journal Portal was used as the database with specific descriptors in the 2010 to 2016 period. Only 11 studies presented the inclusion criteria determined in this study. These papers emphasized the gains of the person with ASD in their communication skills through VM. Given the positive results reported in these 11 studies, there is sufficient evidence to conclude that VM is an indicated procedure for teaching a variety of communicative skills for children with ASD. It is possible to conclude that this study summarized interventions that used VM for teaching communication skills, indicating directions for future research.
\end{abstract}

KEYWORDS: Special Education. Autism Spectrum Disorder. Video Modeling. Communication Skills.

\footnotetext{
${ }^{1}$ http://dx.doi.org/10.1590/S1413-65382317000400009

${ }^{2}$ Doutoranda do Programa de Pós-graduação em Educação Especial da Universidade Federal de São Carlos, São Carlos, SP, Brasil. viviane_reb@hotmail.com

${ }^{3}$ Docente do Programa de Pós-graduação em Educação Especial, Departamento de Psicologia, Universidade Federal de São Carlos. São Carlos, SP, Brasil. ameliama@terra.com.br
} 


\section{INTRODUÇÃo}

As características de linguagem das pessoas com Transtorno do Espectro Autista (TEA) devem ser observadas e consideradas, principalmente no direcionamento de intervençóes voltadas para o desenvolvimento das habilidades de comunicação. Estas características são destacadas na literatura como falta de iniciativa para a comunicação, limitaçóes na linguagem receptiva e expressiva, podendo incluir perseveração verbal (permanência no mesmo assunto), ecolalia (repetição de palavras ou frases), fala idiossincrática (uso peculiar de palavras ou frases vinculadas a eventos ou objetos específicos sem relação com o contexto ou com o ouvinte), pobres características prosódicas (ritmo, tom ou afinação), habilidades não verbais pobres (gestos, expressóes faciais, etc.), uma lacuna na iniciação de linguagem espontânea, atenção compartilhada e déficits nas habilidades pragmáticas (funçóes comunicativas e habilidades conversacionais) (BANDA et al., 2010; AMERICAN PSYCHIATRY ASSOCIATION, 2013).

A National Research Council (2001) aponta que 50\% das crianças com TEA permanecerão não verbais por toda a vida ou funcionalmente não verbais, denotando que estas últimas são pessoas que tendem a somente usar a fala para fazer pedidos ou repetir suas frases favoritas em contextos inapropriados. Charlop, Carpenter e Greenberg (2010) destacam que ao contrário das crianças com TEA, as crianças com desenvolvimento típico (DT), utilizam a referência social das pessoas do seu convívio, como a fala, gestos, expressóes faciais e outras habilidades de comunicação para interagir, comunicar e ter acesso a informaçóes específicas de seus ambientes. Neste sentido, a busca em melhorar as habilidades de comunicação em pessoas com autismo, por meio das mais variadas intervençóes, pode facilitar resultados positivos em todos os ambientes de convívio social.

Estudos avaliaram o reconhecimento de expressóes faciais por pessoas com TEA e os resultados revelaram que enquanto crianças com DT olham para a área em volta dos olhos, boca e nariz durante o reconhecimento de uma expressão facial, as crianças com TEA somente olham para a área da boca. Diante desta constatação, o reconhecimento das expressões faciais, torna-se mais difícil para as pessoas com TEA (KLIN et al., 2002; ASHWIN; WHEELWRIGHT; BARON-COHEN, 2006; WALLACE; COLEMAN; BAILEY, 2008; AKMANOGLU, 2015).

Muitas intervençôes estão sendo empregadas para ensinar comportamentos apropriados e diversas habilidades para esta população, incluindo as habilidades comunicativas, tais como: expressóes faciais, vocalizaçóes, gestos, iniciativa para a comunicação, contato visual, dentre outras. No entanto, é de extrema importância que estas práticas sejam baseadas em evidências e uma delas é a Modelagem em Vídeo ${ }^{4}(\mathrm{MV})$ que passou a ser apontada como uma prática baseada em evidência pelo National Autism Center, nos EUA, a partir de 2009. Modelagem em Vídeo é considerada uma prática que favorece a aprendizagem dos indivíduos com TEA, pelo fato desta população preferir e responder melhor às estratégias de ensino por meio de pistas visuais (BELLINI; AKULLIAN, 2007; SHUKLA-MEHTA; MILLER; CALLAHAN, 2010; MASON et al., 2012b;).

Tendo por base a teoria de Bandura (1969), a Modelagem em Vídeo é uma técnica que tem sido bastante utilizada e pesquisada. As pesquisas apontam que esta intervenção

\footnotetext{
${ }^{4}$ Neste estudo foi adotada a traduçâo de Video Modeling por modelagem em vídeo.
} 
tem demonstrado eficácia na aquisição e desenvolvimento de habilidades sociais, de comunicação, habilidades de vida diária, trabalho e desempenho acadêmico para pessoas com TEA (HUANG; WHEELER, 2006). Nikopoulos e Keenam (2003) definem modelagem em vídeo como imitação de alguns comportamentos ou habilidades demonstradas por meio de vídeos por um adulto ou pares. Modelagem em Vídeo é caracterizada por Shukla-Mehta, Miller e Callahan (2010), considerando o seguinte procedimento: a) uma pessoa é convidada a assistir ao vídeo; b) a habilidade a ser desenvolvida é modelada por um adulto ou pares em um contexto de atividade; c) o instrutor fornece estímulos e reforço para a pessoa atender a estímulos relevantes; d) a pessoa imita o comportamento do modelo com a oportunidade de desempenhar as habilidades exibidas no vídeo.

Existem três tipos básicos de intervençôes em MV: Modelagem em Vídeo com outros como modelo (MVO); Automodelagem em Vídeo (AV); Modelagem em vídeo a partir do ponto de vista (MVPV) ${ }^{5}$. Modelagem em Vídeo com outros como modelo (MVO), utiliza um adulto ou pares como modelo que podem ser conhecidos ou não pelo aprendiz (HONG et al., 2016; BELLINI; AKULLIAN, 2007; MCCOY; HERMANSEN, 2007). Automodelagem em Vídeo (AV) é uma forma específica de modelagem em vídeo que utiliza o aprendiz como o modelo para oferecer oportunidades de aprendizagem, visto que ele visualiza a si próprio desempenhando uma tarefa. O Feedforward abrange a gravação do aprendiz enquanto ele está desempenhando o comportamento alvo por meio de estímulo. Deste modo, a gravação é editada de forma a retirar todo o estímulo, ao final, o vídeo editado é apresentado ao aprendiz. Nesta versão final, o aprendiz aparece desempenhando o comportamento alvo independentemente (DOWRICK, 1999; MASON et al., 2016). O POVM é filmado na perspectiva da primeira pessoa, o vídeo é elaborado com a filmadora na altura do ombro de uma pessoa, sendo que as lentes da filmadora representam os olhos do aprendiz e somente as suas mãos estão visíveis no vídeo, realizando o comportamento alvo (SHUKLA-MEHTA; MILLER; CALLAHAN, 2010). Os três tipos de vídeos são explorados e utilizados como intervençóes na literatura internacional para desenvolverem ou melhorarem diversas habilidades de pessoas com TEA e outras deficiências das mais diferentes faixas etárias (HONG et al., 2016).

O primeiro aspecto positivo desta estratégia é a clareza dos passos a serem realizados na implementação da MV, pois exige que o pesquisador/professor elabore vídeos de pouca duração, de preferência múltiplos exemplares, com um modelo demonstrando o comportamento alvo, além de oferecer um dispositivo eletrônico para que a pessoa assista ao vídeo. A disponibilidade de dispositivos móveis como smartphones, tablets, dispositivos portáteis de uma forma geral, tem aumentado a acessibilidade à MV, tornando possível a sua visualização em vários ambientes e a qualquer momento (CIHAK et al., 2010).

Neste sentido, o segundo aspecto positivo a ser destacado na literatura é a característica motivadora do vídeo, pois quando o aprendiz observa o modelo desempenhando um comportamento alvo e este modelo tem acesso a um item que é reforçador para ele, motiva-o a observar os detalhes do vídeo e também a imitar o comportamento do modelo. Kagohara (2010) demonstrou em seus resultados um terceiro aspecto positivo que está relacionado à faci-

${ }^{5}$ Os três tipos de vídeos foram traduzidos neste estudo como: Video Modeling Others- Modelagem em Vídeo com outros como modelo; Video Self-Modeling- Automodelagem em Vídeo; Point-of-view Video Modeling- Modelagem em vídeo a partir do ponto de vista. 
lidade e rapidez na aprendizagem do comportamento alvo pelas pessoas com TEA, bem como a promoção da generalização para outros ambientes, pessoas e materiais, além de manterem o comportamento aprendido depois de meses da finalização da intervenção.

Dentre os três tipos acima apresentados, a literatura aponta que a MVO e AV são citadas mais frequentemente e ambas são identificadas como efetivas para indivíduos com deficiência (BELLINI; AKULLIAN, 2007). Dowrick (1999) aponta que a AV exige mais dedicação em sua elaboração, pois necessita que o aprendiz realize o comportamento alvo por meio de estímulos. Em seguida, este vídeo deve ser editado sem que os estímulos e comportamentos incorretos estejam presentes, exigindo maior tempo na gravação e também na edição. Assim, dada a complexidade na elaboração da AV, a MVO como modelo tem sido adotada pela maioria dos pesquisadores.

Considerando que na literatura internacional as intervençóes em MV, para pessoas com TEA, vêm sendo amplamente divulgadas e exploradas para desenvolver diversas habilidades, faz-se necessário um olhar mais específico voltado para o uso da MV no desenvolvimento de habilidades de comunicação para esta população. Na literatura nacional, há escassez de estudos voltados para esta temática, contudo, a análise e discussão sobre o que já foi produzido nestes estudos poderão também favorecer a divulgação e incentivo de pesquisas em âmbito nacional para beneficiarem as pessoas com TEA e outras deficiências. Neste sentido, o objetivo desta revisão foi discutir os resultados das intervençóes que implementaram a MV para ensinar habilidades de comunicação para indivíduos com TEA. Para tanto, algumas questóes de pesquisa surgiram: Quais estudos foram desenvolvidos envolvendo o uso da MV voltados para as habilidades de comunicação das pessoas com TEA? Quais os resultados efetivos alcançados pela MV no ensino das habilidades de comunicação para as pessoas com TEA?

\section{DesenVolvimento}

\subsection{MÉTOdo}

Três critérios de inclusão foram estabelecidos para que os estudos fossem incorporados nesta revisão, sendo eles: a) os estudos deveriam utilizar como variável independente a modelagem em vídeo isoladamente, associada a uma outra intervenção ou como parte de um pacote de tratamentos; b) as habilidades de comunicação deveriam fazer parte da variável dependente, mesmo que estivessem presentes outras habilidades; c) todos os estudos deveriam ter participantes com Transtorno do Espectro Autista, mesmo que houvessem participantes com outros diagnósticos.

Foi utilizado como banco de dados o Portal de Periódico da CAPES que compreende mais de 38 mil periódicos completos (como exemplo temos: ERIC- Educational Resources Information Center; IndexPsi- Index Psi Periódicos; PubMed Central: PMC; SciELO- Scientific Electronic; LILACS- Literatura Latino-americana e do Caribe em Ciências da Saúde; Pepsic Periódicos Eletrônicos em Psicologia, dentre outros). Descritores específicos foram utilizados na pesquisa: video modeling and autism, video modeling and communication, video instruction, Asperger syndrome and video modeling, social skills and video modeling, autismo e modelagem em vídeo, modelagem em vídeo e comunicação, modelagem em vídeo. O período determinado 
neste estudo foi de 2010 a 2016. Considerando este período, foram encontrados 120 artigos, mas somente 11 apresentavam os critérios de inclusão determinados neste estudo.

\subsection{Resultados}

Foram revisados um total de 11 estudos que atenderam ao critério de inclusão. $\mathrm{O}$ Quadro 1, apresenta síntese dos participantes, além de descrição de cada estudo envolvendo aspectos metodológicos e principais resultados. O Quadro 2, apresenta características específicas das intervençóes em VM, tais como: tipo de vídeo, tipo de modelo e tempo dos vídeos, além das variáveis dependentes e independentes do estudo.

\subsubsection{Participantes dos estudos}

Os participantes desses estudos foram 36, com idade de 3 a 36 anos, destes, somente um apresentava diagnóstico de síndrome de Down, todos os outros eram diagnosticados com TEA. Destes, 27 são do sexo masculino, seis são do sexo feminino e três dos participantes não tiveram seus sexos declarados.

A maioria dos participantes, 30, foram declarados com diagnóstico de TEA, destes, dois foram declarados com síndrome de Asperger, dois foram diagnosticados com atraso no desenvolvimento e um com síndrome de Down.

As idades variaram de três a 36 anos. Estabeleceu-se, neste estudo, três grupos de acordo com a faixa etária, sendo o primeiro grupo compreendido por participantes de três a seis anos; segundo grupo de sete a 12 anos; terceiro grupo de 14 a 36 anos. O primeiro grupo de três e seis anos conta com 19 participantes, o segundo grupo compreende as idades entre sete e 12 anos com 12 participantes, o terceiro grupo, de 14 aos 36 anos, conta com cinco participantes.

O número de participantes nos estudos variou de um a seis participantes. Seis estudos tiveram entre um e três participantes [2,3,6,8,10,11]. Quatro estudos tiveram quatro participantes $[1,5,7,9]$. Um estudo somente teve seis participantes [4].

\subsubsection{LOCAL}

Os estudos foram conduzidos em sua maioria em Escola Especial, ( $\mathrm{n}=7$ ) $[2,3,5,7,8,9]$. Dois estudos foram realizados em universidades: um envolvia projetos de atendimentos a crianças com autismo e o outro correspondia a um projeto voltado a universitários com síndrome de Asperger $[1,6]$. Dois não declararam o local em que a pesquisa ocorreu $[4,10]$. Somente um realizou-se em uma clínica [11]. 


\begin{tabular}{|c|c|c|c|c|c|c|c|}
\hline Autores & $\begin{array}{l}\text { Participantes } \\
\text { (com TEA) }\end{array}$ & Palavras-chave & Delineamento & Resultados & $\begin{array}{c}\text { Generalizaçáo e } \\
\text { Manutençáo }\end{array}$ & $\begin{array}{c}\text { Vali- } \\
\text { dade } \\
\text { social }\end{array}$ & $\begin{array}{l}\text { Tratamento de } \\
\text { Fidedignidade }\end{array}$ \\
\hline $\begin{array}{l}\text { [1]Akmano- } \\
\text { glu (2015) }\end{array}$ & $4(4,5$ e 6 anos $)$ & $\begin{array}{l}\text { Autismo. } \\
\text { Modelagem em } \\
\text { vídeo. Emoçōes. } \\
\text { Nomeação } \\
\text { de expressōes } \\
\text { faciais. Pesquisas } \\
\text { de sujeito único }\end{array}$ & $\begin{array}{l}\text { Múltiplas } \\
\text { sondagens } \\
\text { através de com- } \\
\text { portamentos }\end{array}$ & $\begin{array}{l}\text { O ensino de nomea- } \\
\text { ção das emoçốes por } \\
\text { meio de expressốes } \\
\text { faciais utilizando o } \\
\text { MV para crianças } \\
\text { com TEA foi efetivo, } \\
\text { além de manterem } \\
\text { e generalizaram a } \\
\text { capacidade após o } \\
\text { final do estudo. }\end{array}$ & $\begin{array}{l}\text { Generalização } \\
\text { através de ma- } \\
\text { teriais, pessoas } \\
\text { e ambientes. } \\
\text { Manutenção: } \\
\text { 1,3 e } 5 \text { semanas } \\
\text { depois. }\end{array}$ & $(+)$ & $\begin{array}{l}\text { Concordância } \\
\text { entre observa- } \\
\text { dores: } 100 \% \text {; } \\
\text { Tratamento de } \\
\text { Fidedignidade: } \\
100 \% \text {. }\end{array}$ \\
\hline $\begin{array}{l}\text { [2]Banda et } \\
\text { al. }(2010)\end{array}$ & 2 (17 e 21 anos) & $\begin{array}{l}\text { Autismo. Mode- } \\
\text { lagem de vídeo. } \\
\text { Comunicaçáo } \\
\text { Suplementar } \\
\text { e Alternativa. } \\
\text { Comunicação }\end{array}$ & $\begin{array}{l}\text { Linha de Base } \\
\text { Múltipla }\end{array}$ & $\begin{array}{l}\text { Os resultados } \\
\text { mostram que ambos } \\
\text { os participantes } \\
\text { solicitaram itens } \\
\text { preferenciais usando } \\
\text { o dispositivo que } \\
\text { gera voz (SGD) com } \\
\text { resultados variáveis } \\
\text { após a introdução da } \\
\text { intervenção. }\end{array}$ & $\begin{array}{l}\text { Generaliza- } \\
\text { çáo atráves } \\
\text { de materiais. } \\
\text { Manutenção: } \\
1 \text { e } 3 \text { semanas } \\
\text { depois. }\end{array}$ & $(+)$ & $\begin{array}{l}\text { Concordância en- } \\
\text { tre observadores: } \\
23 \% \text { de todas as } \\
\text { sessőes; } 93,5 \% \text {; } \\
\text { Tratamento de } \\
\text { Fidedignidade: } \\
23 \% \text { de todas } \\
\text { as sessóes, P1 } \\
(93,3 \%), \text { P2 } \\
(100 \%) \text {. }\end{array}$ \\
\hline $\begin{array}{l}\text { [3]Charlop } \\
\text { et al. (2010) }\end{array}$ & $\begin{array}{l}3(7,8 \text { e } 11 \\
\text { anos) }\end{array}$ & $\begin{array}{l}\text { Afeto. Autismo. } \\
\text { Expressăo } \\
\text { Facial. Gestos. } \\
\text { Entonaçăo. } \\
\text { Modelagem em } \\
\text { vídeo. }\end{array}$ & $\begin{array}{l}\text { Linha de Base } \\
\text { Múltipla }\end{array}$ & $\begin{array}{l}\text { Os resultados do pre- } \\
\text { sente estudo indicam } \\
\text { que a modelagem em } \\
\text { vídeo promoveu com } \\
\text { sucesso comporta- } \\
\text { mentos socialmente } \\
\text { expressivos em } \\
\text { três crianças com } \\
\text { autismo }\end{array}$ & $\begin{array}{l}\text { Generalização } \\
\text { através de pes- } \\
\text { soas, ambientes, } \\
\text { estímulos e } \\
\text { pares. Manuten- } \\
\text { çấo: (-). }\end{array}$ & $(+)$ & $\begin{array}{l}\text { Concordância } \\
\text { entre observado- } \\
\text { res: } 1 / 3 \text { de todas } \\
\text { as sessóes; } 90 \% \text {; } \\
\text { Tratamento de } \\
\text { Fidedignidade: } \\
1 / 3 \text { de todas as } \\
\text { sessôes; } 90 \% \text {. }\end{array}$ \\
\hline $\begin{array}{l}\text { [4]Chen, Lee } \\
\text { e Lin (2016) }\end{array}$ & $\begin{array}{l}6 \text { (idades entre } \\
11 \text { e } 13 \text { anos) }\end{array}$ & $\begin{array}{l}\text { Realidade } \\
\text { aumentada. } \\
\text { Indicador visual. } \\
\text { Apoio visual. } \\
\text { Modelagem em } \\
\text { vídeo. Dicas } \\
\text { sociais não } \\
\text { verbais. }\end{array}$ & $\begin{array}{l}\text { Linha de Base } \\
\text { Múltipla }\end{array}$ & $\begin{array}{l}\text { A intervenção for- } \\
\text { neceu um aumento } \\
\text { no indicador visual, } \\
\text { tem efetivamente } \\
\text { atraído e mantido a } \\
\text { atençáo das crianças } \\
\text { com autismo para } \\
\text { dicas sociais não } \\
\text { verbais e ajudando- } \\
\text {-os a melhorarem o } \\
\text { entendimento das } \\
\text { expressôes faciais e } \\
\text { emoçóes presentes } \\
\text { no livro de histórias. }\end{array}$ & $\begin{array}{l}\text { Generalização } \\
(-) . \text { Manuten- } \\
\text { ção: } 4 \text { semanas } \\
\text { depois. }\end{array}$ & $(-)$ & $\begin{array}{l}\text { Concordância en- } \\
\text { tre observadores: } \\
\text { (-); Tratamento } \\
\text { de Fidedignida- } \\
\text { de: (-). }\end{array}$ \\
\hline $\begin{array}{l}\text { [5]Cihak et } \\
\text { al. (2012) }\end{array}$ & 4 (3 anos) & $\begin{array}{l}\text { Modelagem em } \\
\text { vídeo. Autismo. } \\
\text { Comunicação. } \\
\text { PECS }\end{array}$ & $\begin{array}{l}\text { Delineamento } \\
\text { de tratamentos } \\
\text { alternados }\end{array}$ & $\begin{array}{l}\text { Os autores } \\
\text { concluíram que } \\
\text { os estudantes } \\
\text { aprenderam a usar o } \\
\text { PECS e aumenta- } \\
\text { ram as iniciaçóes } \\
\text { independentes para } \\
\text { a comunicação. No } \\
\text { entanto os estu- } \\
\text { dantes aprenderam } \\
\text { mais rápido quando } \\
\text { usaram o PECS asso- } \\
\text { ciado à modelagem } \\
\text { em vídeo. }\end{array}$ & $\begin{array}{l}\text { Generalização } \\
(-) \text {. Manuten- } \\
\text { çăo: (-). }\end{array}$ & $(+)$ & $\begin{array}{l}\text { Concordância } \\
\text { entre observado- } \\
\text { res: } 50 \% \text { de todas } \\
\text { as sessōes; } 93 \% \text {; } \\
\text { Tratamento de } \\
\text { Fidedignidade: } \\
40 \% \text { de todas as } \\
\text { sessōes, } 95 \% \text {. }\end{array}$ \\
\hline
\end{tabular}




\begin{tabular}{|c|c|c|c|c|c|c|c|}
\hline Autores & $\begin{array}{l}\text { Participantes } \\
\text { (com TEA) }\end{array}$ & Palavras-chave & Delineamento & Resultados & $\begin{array}{c}\text { Generalização e } \\
\text { Manutenção }\end{array}$ & $\begin{array}{l}\text { Vali- } \\
\text { dade } \\
\text { social }\end{array}$ & $\begin{array}{l}\text { Tratamento de } \\
\text { Fidedignidade }\end{array}$ \\
\hline $\begin{array}{l}\text { [6]Mason et } \\
\text { al. (2012a) }\end{array}$ & $\begin{array}{l}2(26 \text { e } 19 \\
\text { anos). }\end{array}$ & $\begin{array}{l}\text { Transtorno } \\
\text { do Espectro } \\
\text { Autista. Ensino } \\
\text { superior. De- } \\
\text { lineamento de } \\
\text { sujeito único. } \\
\text { Intervençáo } \\
\text { baseada em } \\
\text { modelagem em } \\
\text { vídeo }\end{array}$ & $\begin{array}{l}\text { Linha de } \\
\text { base múltipla } \\
\text { através de com- } \\
\text { portamentos }\end{array}$ & $\begin{array}{l}\text { Os resultados apon- } \\
\text { taram mudanças } \\
\text { para todas as habili- } \\
\text { dades alvo para um } \\
\text { participante e para o } \\
\text { outro foram obtidos } \\
\text { contato visual e } \\
\text { conversaçáo. }\end{array}$ & $\begin{array}{l}\text { Generalização: } \\
\text { (-). Manuten- } \\
\text { ção: parcial, } \\
\text { após } 1 \text { semana. }\end{array}$ & $(-)$ & $\begin{array}{l}\text { Concordância en- } \\
\text { tre observadores: } \\
\text { (-); Tratamento } \\
\text { de Fidedignida- } \\
\text { de: (-). }\end{array}$ \\
\hline $\begin{array}{l}\text { [7]Plavnick } \\
\text { e Ferreri } \\
(2011)\end{array}$ & $\begin{array}{l}4(4,5 \text { a } 6,5 \\
\text { anos) }\end{array}$ & $\begin{array}{l}\text { Autismo. Aná- } \\
\text { lise Funcional. } \\
\text { Aprendizagem } \\
\text { observacional. } \\
\text { Comporta- } \\
\text { mento verbal. } \\
\text { Modelagem em } \\
\text { vídeo. }\end{array}$ & $\begin{array}{l}\text { Experimento } \\
\text { 1: tratamentos } \\
\text { alternados. } \\
\text { Experimento } \\
\text { 2: tratamentos } \\
\text { alternados } \\
\text { e múltiplas } \\
\text { sondagens. }\end{array}$ & $\begin{array}{l}\text { Experimento 1: } \\
\text { Os gestos foram } \\
\text { variados em cada } \\
\text { condiçáo e também } \\
\text { para cada partici- } \\
\text { pante. Experimento } \\
\text { 2: os resultados } \\
\text { dos estudos atuais } \\
\text { demonstraram que } \\
\text { os procedimentos de } \\
\text { modelagem de vídeo } \\
\text { baseados na funçấo } \\
\text { identificada do } \\
\text { comportamento co- } \\
\text { municativo são mais } \\
\text { eficazes no ensino } \\
\text { de novas respostas } \\
\text { comunicativas do } \\
\text { que os procedimen- } \\
\text { tos de modelagem } \\
\text { em vídeo que năo } \\
\text { estão relacionados a } \\
\text { relaçóes funcionais } \\
\text { identificadas. }\end{array}$ & $\begin{array}{l}\text { Experimento 1: } \\
\text { Generalização } \\
\text { (-). Manutenção } \\
\text { (-). Experimen- } \\
\text { to 2: Generaliza- } \\
\text { ção através de } \\
\text { ambiente, situa- } \\
\text { çôes, estímulos. } \\
\text { Manutenção: } 1 \text {, } \\
2,4 \text { e } 8 \text { semanas } \\
\text { depois. }\end{array}$ & $(+)$ & $\begin{array}{l} \\
\text { Experimento 1: } \\
\text { Concordância en- } \\
\text { tre observadores: } \\
\text { (-). Tratamento } \\
\text { de Fidedignidade: } \\
20 \% \text { de todas } \\
\text { as sessőes, } 98 \% \text {. } \\
\text { Experimento } 2: \\
\text { Concordância en- } \\
\text { tre observadores: } \\
\text { (-). Tratamento } \\
\text { de Fidedignidade: } \\
20 \% \text { de todas as } \\
\text { sessóes, } 96 \% \text {. }\end{array}$ \\
\hline $\begin{array}{l}\text { [8]Plavnick } \\
(2012)\end{array}$ & 1 (4 anos) & $\begin{array}{l}\text { Autismo. } \\
\text { Treinamento } \\
\text { de comunica- } \\
\text { ção. Imitação. } \\
\text { Tecnologia. } \\
\text { Modelagem em } \\
\text { vídeo. }\end{array}$ & Critério móvel & $\begin{array}{l}\text { O participante } \\
\text { demonstrou rápida } \\
\text { melhora na atençấo } \\
\text { para uma tela de } \\
\text { vídeo portátil; MV } \\
\text { foi entấo usado para } \\
\text { ensinar o participan- } \\
\text { te a pedir eventos } \\
\text { preferidos usando a } \\
\text { troca de figuras. }\end{array}$ & $\begin{array}{l}\text { Generalização } \\
\text { através de } \\
\text { ambiente. Ma- } \\
\text { nutenção: (-). }\end{array}$ & $(-)$ & $\begin{array}{l}\text { Concordância en- } \\
\text { tre observadores: } \\
22 \% \text { de todas as } \\
\text { sessōes, } 92 \% \text { para } \\
\text { atenção e } 100 \% \\
\text { para imitação. } \\
\text { Tratamento de } \\
\text { Fidedignidade: } \\
(-) \text {. }\end{array}$ \\
\hline $\begin{array}{l}\text { [9]Plavnick e } \\
\text { Vitale (2016) }\end{array}$ & 4 (4 anos) & $\begin{array}{l}\text { Transtorno do } \\
\text { Espectro Autis- } \\
\text { ta. Treinamento } \\
\text { de mando. } \\
\text { Controle de } \\
\text { estímulos. Com- } \\
\text { portamento ver- } \\
\text { bal. Modelagem } \\
\text { em vídeo. }\end{array}$ & $\begin{array}{l}\text { Tratamentos } \\
\text { alternados }\end{array}$ & $\begin{array}{l}\text { Os participantes } \\
\text { adquiriram e domi- } \\
\text { naram os mandos } \\
\text { mais rapidamente na } \\
\text { condição de MV do } \\
\text { que na condição ao } \\
\text { vivo. Os resultados } \\
\text { demonstraram o } \\
\text { potencial eficaz do } \\
\text { MV para ensinar } \\
\text { operantes verbais } \\
\text { para crianças com } \\
\text { autismo. }\end{array}$ & $\begin{array}{l}\text { Generalização } \\
(-) \text {. Manuten- } \\
\text { çăo: (-). }\end{array}$ & $(+)$ & $\begin{array}{l}\text { Concordância en- } \\
\text { tre observadores: } \\
\text { (-). Tratamento } \\
\text { de Fidedignidade: } \\
25 \% \text { das sessóes, } \\
94 \% \text { para vivo } \\
\text { modeling e } \\
92 \% \text { para video } \\
\text { modeling. }\end{array}$ \\
\hline
\end{tabular}




\begin{tabular}{|c|c|c|c|c|c|c|c|}
\hline Autores & $\begin{array}{l}\text { Participantes } \\
\text { (com TEA) }\end{array}$ & Palavras-chave & Delineamento & Resultados & $\begin{array}{l}\text { Generalizaçáo e } \\
\text { Manutençáo }\end{array}$ & $\begin{array}{c}\text { Vali- } \\
\text { dade } \\
\text { social }\end{array}$ & $\begin{array}{l}\text { Tratamento de } \\
\text { Fidedignidade }\end{array}$ \\
\hline $\begin{array}{l}{[10] \text { Smith, }} \\
\text { Hand e } \\
\text { Dowrick } \\
(2014)\end{array}$ & $\begin{array}{l}3(9,11 \text { e } 36 \\
\text { anos- SD) }\end{array}$ & $\begin{array}{l}\text { Sistemas de } \\
\text { comunicaçăo. } \\
\text { Aprendizagem } \\
\text { rápida. Video } \\
\text { Self Modeling. } \\
\text { Feeforward. Au- } \\
\text { tismo. Síndrome } \\
\text { de Down. }\end{array}$ & $\begin{array}{l}\text { Delineamento } \\
\mathrm{AB} \text {. }\end{array}$ & $\begin{array}{l}\text { O AV, usando } \\
\text { feedforward pode } \\
\text { fornecer um cami- } \\
\text { nho rápido e simples } \\
\text { para ensinar o uso } \\
\text { do PECS sem que } \\
\text { precise de estímulos } \\
\text { ou condicionamento } \\
\text { operante intenso. }\end{array}$ & $\begin{array}{l}\text { Generalização } \\
\text { através de pes- } \\
\text { soas e materiais. } \\
\text { Manutençấo: } 5 \\
\text { semanas depois }\end{array}$ & $(+)$ & $\begin{array}{l}\text { Concordância } \\
\text { entre observado- } \\
\text { res: } 41 \% \text { de todas } \\
\text { as sessōes, } 96 \% \text {. } \\
\text { Tratamento de } \\
\text { Fidedignidade: } \\
41 \% \text { de todas as } \\
\text { sessôes } 98 \% \text {. }\end{array}$ \\
\hline $\begin{array}{l}{[11] \text { Tetreault }} \\
\text { e Lerman } \\
(2010)\end{array}$ & $3(4,5$ e 8 anos $)$ & Nấo tem. & $\begin{array}{l}\text { Linha de Base } \\
\text { Múltipla por } \\
\text { script }\end{array}$ & $\begin{array}{l}\text { Por meio da } \\
\text { intervenção houve } \\
\text { melhora no compor- } \\
\text { tamento social dos } \\
\text { dois participantes, } \\
\text { estímulos foram } \\
\text { necessários para atin- } \\
\text { gir a aquisição pelo } \\
\text { terceiro participante. }\end{array}$ & $\begin{array}{l}\text { Generaliza- } \\
\text { çấo através } \\
\text { de materiais. } \\
\text { Manutenção: } 10 \\
\text { dias depois }\end{array}$ & $(-)$ & $\begin{array}{l}\text { Concordância en- } \\
\text { tre observadores: } \\
\text { 93\%. Tratamento } \\
\text { de Fidedignidade: } \\
99 \% \text {. }\end{array}$ \\
\hline
\end{tabular}

Quadro 1- Características Metodológicas dos Estudos

Fonte: elaboração própria.

Nota: AV- Automodelagem em Vídeo; TEA- Transtorno do Espectro Autista; SGD- Speech-Generating Devices; PECS- Sistema de Comunicação por troca de Figuras; MV - Modelagem em Vídeo; SD- Síndrome de Down

\subsubsection{VariáVel Dependente}

Os estudos registraram muitas variáveis dependentes. $\mathrm{Na}$ maioria deles havia mais de uma variável, todas relacionadas às habilidades de comunicação. Foram agrupadas em seis variáveis. As expressóes faciais estavam presentes em quatro estudos [1,4,6,3]. Fazer pedidos por meio da Comunicação Suplementar e/ou Alternativa estavam presentes em cinco estudos $[2,5,7,8,10]$. A fala apareceu em quatro artigos [6,7,9,11]. Gestos em dois artigos [3,7]. Entonação em um artigo [3]. Contato visual em um artigo [6].

\subsubsection{VARIÁVEL INDEPENDENTE}

Todos os estudos apresentaram intervençóes em MV, seis estudos apresentaram a intervenção com MV isoladamente [1,2,3,6,7,11]; quatro envolviam MV associado a outra intervenção $[5,8,9,10]$ e um estudo utilizando o MV como componente de um tratamento com múltiplos componentes [4].

\subsubsection{Modelagem em Vídeo: Tipos de MV utilizados/Modelos/ Duração dos VÍDEOS AO SEREM VISTOS PELOS PARTICIPANTES}

Foram utilizados pelos estudos os três tipos de MV: Modelagem em Vídeo com outros como modelo (MVO); Automodelagem em Vídeo (AV); Modelagem em vídeo a partir do ponto de vista (MVPV). O mais utilizado foi o MVO, contanto com 9 artigos [1-9]; AV foi utilizado somente em um estudo [10]; MVPV também foi utilizado em somente um estudo.

Quanto aos modelos selecionados para aparecerem nos vídeos, a maioria dos estudos optou pelo uso de modelo adulto $(n=5)$. Dois estudos utilizaram crianças para serem seus 
modelos [5,7]. Um estudo utilizou os próprios participantes como modelo [10] e um usou a perspectiva da primeira pessoa [11].

A duração dos vídeos variou de 10 s a 2 min e 33 s. Os estudos que apresentaram a duração do vídeo no intervalo de 10 s a 30 s foram três $[2,7,8]$. Com relaçáo aos intervalos de 30 s a $1 \mathrm{~min}$, obteve-se um estudo [4]. Com o intervalo de $1 \mathrm{~min}$ a $3 \mathrm{~min}$, encontram-se três estudos $[6,10,11]$. Quatro estudos não declararam a duração do vídeo utilizado $[1,3,5,9]$.

\begin{tabular}{|c|c|c|c|c|c|}
\hline Autores & Tipo de VM & Variável Dependente & Tipo do Modelo & Variável Independente & Tempo do vídeo \\
\hline $\begin{array}{l}\text { [1] Akmanoglu } \\
(2015)\end{array}$ & $\begin{array}{l}\text { MVO (adulto como } \\
\text { modelo) }\end{array}$ & Expressōes faciais & 1 adulto & Somente MVO & Não especificado \\
\hline $\begin{array}{l}\text { [2] Banda et al. } \\
(2010)\end{array}$ & $\begin{array}{l}\text { MVO (adulto como } \\
\text { modelo) }\end{array}$ & Fazer pedidos & 1 adulto & Somente MVO & 10 a $15 \mathrm{~s}$. \\
\hline $\begin{array}{l}\text { [3] Charlop et } \\
\text { al. (2010) }\end{array}$ & $\begin{array}{l}\text { MVO (adulto como } \\
\text { modelo) }\end{array}$ & $\begin{array}{l}\text { Comportamentos social- } \\
\text { mente expressivos }\end{array}$ & 1 adulto & Somente MVO & Não especificado \\
\hline $\begin{array}{l}\text { [4] Chen, Lee e } \\
\text { Lin (2016) }\end{array}$ & $\begin{array}{l}\text { MVO (adulto e criança } \\
\text { como modelo) }\end{array}$ & $\begin{array}{l}\text { Seis expressóes faciais a } \\
\text { partir de emoçōes }\end{array}$ & 1 Adulto e 1 criança & $\begin{array}{l}\text { MVO+ realidade } \\
\text { aumentada+livro de } \\
\text { histórias }\end{array}$ & 30 a $40 \mathrm{~s}$ \\
\hline $\begin{array}{l}\text { [5] Cihak et al. } \\
\text { (2012) }\end{array}$ & $\begin{array}{l}\text { MVO (uma criança de } \\
4 \text { anos sem deficiência }\end{array}$ & $\begin{array}{l}\text { Iniciaçôes independentes } \\
\text { para a comunicaçấo }\end{array}$ & 1 par & $\mathrm{MVO}+\mathrm{PECS}$ & Não especificado \\
\hline $\begin{array}{l}\text { [6] Mason et al. } \\
\text { (2012a) }\end{array}$ & $\begin{array}{l}\text { MVO } 2 \text { adultos como } \\
\text { modelo ( } 20 \text { e } 31 \text { anos) }\end{array}$ & $\begin{array}{l}\text { Contato visual, expressáo } \\
\text { facial e conversação }\end{array}$ & 2 adultos & MVO & 1 a 2 min. \\
\hline $\begin{array}{l}\text { [7] Plavnick e } \\
\text { Ferreri (2011) }\end{array}$ & $\begin{array}{l}\text { MVO } 2 \text { crianças como } \\
\text { modelo ( } 3 \text { e } 9 \text { anos) }\end{array}$ & $\begin{array}{l}\text { Experimento 1: compor- } \\
\text { tamento verbal (gestos). } \\
\text { Experimento 2: mandos } \\
\text { vocais e mandos por troca } \\
\text { de figuras. }\end{array}$ & 2 crianças & $\begin{array}{l}\text { Experimento 1: Pro- } \\
\text { cedimento de análise } \\
\text { funcional que inclui: } \\
\text { materiais, escape, atençăo } \\
\text { e condiçốes de controle. } \\
\text { Experimento 2: MVO }\end{array}$ & 15 a $27 \mathrm{~s}$ \\
\hline $\begin{array}{l}\text { [8] Plavnick } \\
\text { (2012) }\end{array}$ & $\begin{array}{l}\text { MVO um adulto e } \\
\text { uma criança }\end{array}$ & $\begin{array}{l}\text { Comportamento de pres- } \\
\text { tar atençáo e imitar }\end{array}$ & 1 criança e 1 adulto & $\begin{array}{l}\text { Treinamento de prestar a } \\
\text { atenção e imitar por meio } \\
\text { do MVO (para fazer a } \\
\text { fase I do PECS) }\end{array}$ & $18 s$ \\
\hline $\begin{array}{l}\text { [9] Plavnick e } \\
\text { Vitale (2016) }\end{array}$ & MVO adulto & $\begin{array}{l}\text { Número de mandos } \\
\text { vocais adquiridos e } \\
\text { dominados }\end{array}$ & 1 adulto & $\begin{array}{l}\text { Treinamento de mando } \\
\text { ao vivo e treinamento } \\
\text { de mando por meio do } \\
\text { MVO }\end{array}$ & Não especificado \\
\hline $\begin{array}{l}\text { [10] Smith, } \\
\text { Hand e Dowri- } \\
\text { ck }(2014)\end{array}$ & AV & $\begin{array}{l}\text { Habilidades de comuni- } \\
\text { caçăo por meio da troca } \\
\text { de figuras }\end{array}$ & $\begin{array}{l}\text { Os próprios partici- } \\
\text { pantes }\end{array}$ & AV para ensinar PECS. & $\begin{array}{l}1 \min 8 s \text { a } 2 \mathrm{~min} \\
38 \mathrm{~s}\end{array}$ \\
\hline $\begin{array}{l}\text { [11] Tetreault e } \\
\text { Lerman }(2010)\end{array}$ & $\begin{array}{l}\text { MVPV- Perspectiva da } \\
\text { própria pessoa e um } \\
\text { PC adulta }\end{array}$ & $\begin{array}{l}\text { Habilidades de comunica- } \\
\text { ção, mais especificamente } \\
\text { de conversação. }\end{array}$ & $\begin{array}{l}\text { Perspectiva da } \\
\text { primeira pessoa }\end{array}$ & $\begin{array}{l}\text { MVPV para ensinar a } \\
\text { iniciar e manter uma } \\
\text { conversa }\end{array}$ & $\begin{array}{l}2 \mathrm{~min} 21 \mathrm{~s} \text { a } 2 \mathrm{~min} \\
\mathrm{e} 33 \mathrm{~s}\end{array}$ \\
\hline
\end{tabular}

\section{Quadro 2- Características das Intervençóes de Modelagem em Vídeo}

Fonte: elaboração própria.

Nota: VMO- Video Modeling Outros; VSM- Video Self-Modeling; POVM- Point-of-view Video Modeling;

PECS- Sistema de Comunicação por troca de Figuras; PC: Parceira de Comunicação 


\subsubsection{Tratamento de Fidedignidade e Concordância Inter observador/ Genera- lizaçáo e Manutençấ/ Validade Social}

A generalização se realizou por meio de ambientes, materiais, pessoas e estímulos, realizaram este procedimento somente seis estudos $[1-3,7,8,10]$; a manutenção teve variação de uma semana a oito semanas, sendo um procedimento realizado em sete estudos $[1,2,4,6,7,10,11]$. A validade social foi realizada em sete estudos $[1-3,5,7,9,10]$.

\section{CONSIDERAÇÓES FINAIS}

A finalidade desta revisão foi contribuir para a área de educação especial com uma estratégia que vem sendo muito explorada na literatura internacional e tem mostrado a sua eficácia a pessoas com TEA. A Modelagem em Vídeo é uma estratégia que vem sendo utilizada para o ensino de diversas habilidades, este estudo sumarizou intervenções que empregaram a MV para o ensino de habilidades de comunicação. Estes estudos enfatizaram os ganhos das pessoas com TEA em suas habilidades de comunicação por meio da MV.

As habilidades de comunicação são fundamentais para a interação com as outras pessoas, está extremamente vinculada às habilidades sociais. Os estudos analisados apresentaram habilidades de comunicação como: as expressóes faciais, fazer pedidos por meio da Comunicação Suplementar e/ou Alternativa, fala, gestos, entonação e contato visual. Observase que a linguagem não verbal esteve em maior número comparada à linguagem verbal, este fato se deve às características das pessoas com TEA, considerando que $25 \%$ a $30 \%$ das pessoas com este diagnóstico são não verbais (NAIGLES, 2017). Estratégias que estão voltadas exclusivamente para a fala, podem não ser eficazes para grande parte desta população.

A Modelagem em Vídeo com outros como modelo, destacou-se em relação aos outros tipos de vídeo, utilizaram como modelo adultos e pares, permanecendo com a maioria adultos. Mais estudos devem explorar os outros tipos de vídeos e também outros tipos de modelos, para, desta forma, buscar comparar qual modelo e qual tipo de vídeo é mais eficaz. Outra questáo a ser destacada é a duraçáo do vídeo, variando muito, seria importante que os estudos destacassem a duraçáo do vídeo e como os participantes responderam à essa duraçáo para que pesquisas futuras consigam chegar a uma duração que seja suficiente para ensinar pessoas com TEA e também que seja mais adequada às especificidades desta população.

Quanto ao ambiente em que ocorreram as intervençóes, a maioria ocorreu em escolas especiais, havendo necessidade de expandir para outros ambientes como casa e também comunidade em geral, para que a comunicação seja funcional e, por conseguinte, aconteça a generalização das habilidades desenvolvidas, o que não ocorreu em grande parte dos estudos. Caso contrário a aprendizagem fica restrita a um único ambiente, posto que se a família náo compreender todo o processo e não estiver envolvida nele, a intervenção terá poucas oportunidades de continuidade.

A generalização foi realizada por meio de ambientes, materiais, pessoas e estímulos. Este procedimento foi realizado em aproximadamente metade dos estudos, sendo que é um procedimento fundamental, principalmente quando se refere às habilidades de comunicação. Da mesma forma, a manutenção e a validade social também foram realizadas em aproximadamente metade dos estudos, sendo procedimentos fundamentais para demonstrarem validade interna e externa dos estudos. 
Apesar destas limitaçôes, os resultados gerais desta revisão parecem apoiar o uso da modelagem em vídeo na reabilitação de crianças com TEA. Dados os resultados positivos relatados nestes 11 estudos, há evidências suficientes para concluir que a modelagem em vídeo é um procedimento empiricamente comprovado para ensinar uma variedade de habilidades comunicativas para crianças com TEA. Não obstante, deve-se considerar a variedade diagnóstica desta população para que a intervenção seja mais adequada.

\section{REFERENCIAS}

AKMANOGLUA, N. Effectiveness of teaching naming facial expression to children with autism via video modeling. Educational Sciences: Theory and practice, Istanbul, v.15, n.2, p.519-537, 2015.

AMERICAN PSYCHIATRY ASSOCIATION. Diagnostic and statistical manual of mental disorders DSM-5. 5th.ed. Washington: American Psychiatric Association, 2013.

ASHWIN, C.; WHEELWRIGHT, S.; BARON-COHEN, S. Attention bias to faces in Asperger Syndrome: A pictorial emotion stroop study. Psychological Medicine, Cambridge, v.36, p.835-843, 2006.

BANDA, D.R. et al. Video modeling interventions to teach spontaneous requesting using AAC devices to individuals with autism: a preliminary investigation. Disability and Rehabilitation, London, v.32, n.16, p.1364-137, 2010.

BANDURA, A. Social learning of moral judgments. Journal of Personality and Social Psychology, v.11, p.275-279, 1969.

BELLINI, S.; AKULLIAN, J. A meta-analysis of video modeling and video self-modeling interventions for children and adolescents with autism spectrum disorders. Exceptional Children, London, v.73, p.264-287, 2007.

CHARLOP, M.H.; CARPENTER, M.H.; GREENBERG, A.L. Teaching socially expressive behaviors to children with autism through video modeling. Education and Treatment of Children, Morgantown, v.33, p.371-393, 2010.

CHEN, C.; LEE, I.; LIN, L. Augmented reality-based video-modeling storybook of nonverbal facial cues for children with autismo spectrum disorder to improve their perceptions and judgments of facial expressions and emotions. Computers in Human Behavior, Amsterdam, v.55, p.477-485, 2016.

CIHAK, D.F et al. The use of videomodeling via a video iPod and a system of least prompts to improve transitional behaviors for students with autism spectrum disorders in the general education classroom. Journal of Positive Behavior Interventions, London, v.12, p.103-115, 2010.

CIHAK, D.F. et al. The use of video modeling with the picture exchange communication system to increase independent communicative initiations in preschoolers with autism and developmental delays. Focus on Autism and Other Developmental Disabilities, London v.27, n.1, p.3-11, 2012.

DOWRICK, P.W. A review of self modeling and related interventions. Applied and Preventive Psychology, Kansas, v.8, p.23-29, 1999.

HONG, E. R. et al. The effects of video modeling in teaching functional living skills to persons with ASD: A meta-analysis of single-case studies. Reasearch in Developmental Disabilities, Kansas, v.57, p.158-169, 2016.

HUANG, A.X.; WHEELER, J. J. High-functional autism: An overview of characteristics and related issues. International Journal of Special Education, v.21, n.2, p.109-122, 2006. 
KAGOHARA, D.M. Is video-based instruction effective in the rehabilitation of children with autism spectrum disorders? Developmental Neurorehabilitation, London, v.13, n.2, p.129-140, 2010.

KLIN, A. et al. Visual fixation patterns during viewing of naturalistic social situations as predictors of social competence in individuals with autism. Archives of General Psychiatry, Bethesda, v.59, p.809-816, 2012.

MASON, R. A. et al. Video self-modeling for individuals with disabilities: A best-evidence, single case meta-analysis. Journal of Developmental and Physical Disabilities, New York, v.28, p.623-642, 2016.

MASON, R.A. et al. Effects of video modeling on communicative social skills of college students with asperger syndrome. Developmental Neurorehabilitation, London, v.15, n.6, p. 425-434, 2012a.

MASON, R.A. et al. Moderating factors of videomodeling with other as model: A meta-analysis of single-case studies. Research in Developmental Disabilities, Kansas, v.33, n.4, p.1076-1086, 2012b.

MCCOY, K.; HERMANSEN, E. Video Modeling for individuals with autism: review of model types and effects. Education and Treatment of Children, Morgantown, v.30, n.4, p.183-213, 2007.

NAIGLES, L.R. Innovative investigations of language in autism spectrum disorder. Washington, DC: American Psychological Association, 2017, 255 p.

NATIONAL AUTISM CENTER. A parent's guide to evidencebased practice and autism: Providing information and resources for families of children with autism spectrum disorders. Randolph, Massachusetts, 2011.

NATIONAL RESEARCH COUNCIL. Educating children with autism. Washington, DC: National Academy Press, 2001.

NIKOPOULOS, C.K; KEENAN M. Promoting social initiation children with autism using video modeling. Journal of Positive Behavior Interventions, Thousand Oaks, v.18, p.87-108, 2003.

PLAVNICK, J.B. A Practical strategy for teaching a child with autism to attend to and imitate a portable video model. Research an Practice for Persons with Severe Disabilities, Thousand Oaks, v.37, n.4, p.263-270, 2012.

PLAVNICK, J.B.; VITALE, F.A. A comparison of vocal mand training strategies for children with autism spectrum disorders. Journal of Positive Behavior Interventions, v.18, n.1, p.52-62, 2016.

PLAVNICK, J.B.; FERRERI, S.J. Establishing verbal repertoires in children with autism using functionbased video modeling. Journal of Applied Behavior Analysis, Thousand Oaks, v.44, p.747-766, 2011.

SHUKLA-MEHTA, S.; MILLER, T.; CALLAHAN, K.J. Evaluating the effectiveness of video instruction on social and communication skills training for children with autism spectrum disorders: A review of the literature. Focus on Autism and Other Developmental Disabilities, London, v.25, n.1, p.23-36, 2010.

SMITH, J.; HAND, L.; DOWRICK, P.W. Video feedforward for rapid learning of a picture-based communication system. Journal of Autism Developmental Disorders, New York, v.44, n.4, p.926-936, 2014.

TETREAULT, A.S.; LERMAN, D.C. Teaching social skills to children with autism using point-ofview video modeling. Education and Treatment of Children, Morgantown, v. 33, p. 395-419, 2010.

WALLACE, S.; COLEMAN, M.; BAILEY, A. An investigation of basic facial expression recognition in autism spectrum disorders. Cognition and Emotion, Pennsylvania, v.22, p.1353-1380, 2008.

Recebido em: 10/02/2017

Reformulado em: 25/05/2017

Aprovado em: 02/08/2017 